\title{
The Pragmatic Study of Sentence Final Particle ba
}

\author{
Huafeng Wang \\ Faculty of English Language and Culture, Guangdong University of Foreign Studies \\ 2, Baiyun Avenue North, Baiyun District, Guangzhou 510420, China (North Campus) \\ * E-mail of the corresponding author:20200110064@gdufs.edu.cn
}

\begin{abstract}
Abstract from The Pragmatic Study of Sentence Final Particle ba by Wang Huafeng: With the background of deficient studies on Chinese sentence final particle $b a$, this paper applies the theoretical framework of speech act theory to analyze pragmatic properties of $b a$ in conventional discourse. The current study aims to investigate which clause types that $b a$ can attach to with minimal pairs and explore speaker's various illocutionary force through the occurrence of sentence final particle $b a$ in different clause types. By virtue of small-scale quantitative and qualitative methods, it is concluded that $b a$ can appear in declaratives, interrogatives, imperatives and exclamatives and bring about different illocutionary force when occurring in various clause types.
\end{abstract}

Keywords: sentence final particle $b a$; speech act theory; illocutionary force

DOI: $10.7176 /$ JLLL/81-03

Publication date:August $31^{\text {st }} 2021$

\section{Introduction}

1.1 Research Orientation

The present study aims to investigate, within Speech Act Theory (SAT) proposed by Austin (1962), the pragmatic effects of sentence final particle (SFP) $b a$ in conventional utterance. Two research questions are explored in the present study: (1) What are the clause types that $b a$ can attach to? (2) What are the pragmatic functions of sentence final particle $b a$ ?

\subsection{Rational and Significance for the Present Study}

Having sorted out the previous studies of particle $b a$, the current article is theoretically and practically taking several dimensions into consideration. Firstly, from the perspective of semantics, previous researches paid more attention to the development, original word meaning of $b a$ or the comparison of $b a$ to another particle in other languages, like Japanese (Song 2002; Tong \& Sun 2005; Ren 2021; Xu 2015; Zhang 2012; Zeng 2012), ignoring the sentence meaning or context meaning. Secondly, within the study of syntax, discussion of clause types that $b a$ could be attached to is relatively not enough, in spite of probing into the syntactic position or a variant format on the choice of personal pronoun, like "V (Vp) + Ba + Ni". (Wang 2009; Jin 2016; Jin 2018; Yuan 2003). While as for pragmatic dimension, there are large quantities of studies differentiating Chinese Mandarin particle, such as " $m a$ " " $n e$ " " $w a$ " " $a$ " " $y a$ " or examining children language acquisition of $b a$ (Lee-Wong 1998; Zhang \& Wang 2018; Zhang 2012; Liu 2014; Zeng 2012), rarely mentioning the illocutionary force of ba only.

Therefore, aiming at narrowing the gap between them and shedding some light on pragmatic functions of SFP $b a$, we decided to concentrate on the pragmatic properties of $b a$ in conventional discourse. Furthermore, with no alternative in English, SFP is a unique part of speech in Chinese bestowed certain pragmatic properties. And it is one of the characteristics of Chinese that speakers employ SFPs to convey various intentions or moods of addressers. Accordingly, such investigation is significant to help the world know more about specific Chinese characters. What's more, unlike content words naming thoughts and objects, functional words or SFPs are also necessary to signify the solidarity, opposition, suspicion, emphasis, etc. of ideas or propositions. For Chinese language system, function words (i.e. SFPs) are more flexibly utilized as indicators of a transition from one thought to another than as explicit grammatical markers (Wilhelm Von Humbolot 1826).

In all, there are lots of studies on Chinese particles, studies on $b a$ from pragmatics seem to be deficient. It is hoped to explore which clause types that $b a$ can attach to and the pragmatic functions of sentence final particle $b a$. It is also prospected that the current survey can to some extent enlighten us to think that the occurrence of sentence final particle $b a$ in the speech acts depends on the speaker's intention.

\subsection{Organization of the Present Study}

Following this part of introduction to the orientation and rationale of the present study, part two will review the related literature, which covers the development and categories of Speech Act Theory, certain definition or clarification of illocutionary force, as well as provides the previous contribution to SFP $b a$ from the perspective of semantics, syntax and pragmatics.

Part three presents a detailed quantitative and qualitative description of the current investigation on sentence 
final particle $b a$ within pragmatic function, consisting of research methodology, data collection and contextual interpretation with minimal pairs from corpus and self-cognition.

Part four summarizes two major research findings. Limitations of this study are listed and suggestions of further research are also proposed.

\section{Review of the related literature}

\subsection{Overview}

As mentioned above, the purpose of the present study is to explore which clause types that $b a$ can attach to and pragmatic functions of sentence-final particle $b a$, based on the the Speech Act Theory. From the above statement that to achieve this purpose, the current study has to be reviewed in two dimensions so that it can be grounded on more valid theoretical and conventional examples.

In the first part, it is emphasized Speech Act Theory and illocutionary force, so as to provide a wellorganized combined theoretical structure. In the second part, the present study rationales an overview of the previous contributions to SFP $b a$ from three angles: semantics, syntax and pragmatics, which not only presents the empirical basis in the sense that methodology and data analysis used in these studies can be drawn upon, but also serves as a framework of reference against which the results of the present study can be compared to.

\subsection{Speech Act Theory}

\subsubsection{A brief introduction}

The ideal language approach of the formalists, such as Frege, Russel, advocated "the logical positivism" and the principle of verifiability: if there was no way of working out whether a particular sentence was true or false (or "verifying" it), then that sentence was meaningless (Levinson 1983). Holding the idea that not all sentences could be used by truth-conditional judgment, J. L. Austin, the Oxford philosopher developed speech act theory, whose 1955 James William Lectures at Harvard University was How to Do Things with Words. The profound slogan is "Saying is (part of) doing, or words are (part of) deeds".

Austin proposed the first dichotomy: the distinction between performative utterance and constative utterance. Performatives refer to performing some acts and could be verified as being true of false. While constatives are "utterances for which a truth value conceivably could be determined" (Holtgraves 2002). However, it's hard to classify which utterance is performative or constative systematically, three facets of a speech act was replaced. More accounts for this rejection focus on the phenomenon that all utterances are performative, including the claim itself.

Then Austin established another model to explain the way acts are performed by utterances--a speaker experiences three acts simultaneously when uttering: a locutionary act, an illocutionary act and a perlocutionary act. Searle, as the student of Austin, propelled the development of speech act by categorizing it into five typologies from the perspective of philosophy other than social conventions: representatives, directives, commissives, expressives and declarations. Having classified the distinction of direct speech act and indirect speech act, Levinson (1983) put forward the literal force hypothesis, i.e. each clause type matches a function (an illocutionary force). Specifically, declaratives match asserting/stating; interrogatives mean asking /questioning and imperatives correspond to ordering/requesting.

2.2.2 Illouctionary act or illouctionary force

On the basis of Austin (1962), the action intended by the speaker was termed as an illocutionary act, which is the act accomplished in speaking and defined within a system of social conventions. More precisely, an illocution explains in what way one is using a locution: "for asking or answering a question, giving some information or an assurance or a warning", etc (Marcu 2000). Besides, the same loctionary act may have distinct illocutionary acts in various contexts. For example, "Mum is coming" can performs the illocutionary act of warning, comforting, threatening, encouraging, etc. in different language environment. In all, the speaker's intention and the context are two significant factors when speculating an illocuctionary act.

In speech act theory, the term illocutionary act refers to the use of a sentence to express an attitude with a certain function or force, named an illocutionary force, which varies from locutionary acts since they carry a certain urgency and appeal to the meaning and direction of the speaker. Accordingly, whether an utterance is an assertion, a question, a command or an expression of wish are all included. For example, "Pass me that book" and "Could you pass me that book" performs an order and request respectively. What's more, there are different devices or illocutionary force markers (IFIDs), used to indicate how an illocutionary force must be interpreted, such as performative verbs, mood, word order, intonation, stress.

\subsection{Previous Studies of Sentence Final Particle ba}

In view of observation like the preceding examples, $b a$ has been discussed in the literature from three dimensions: semantics, syntax and pragmatics. The previous achievements will be reviewed and summarized in this part, as well as some controversies or counterparts. 


\subsubsection{Semantic studies}

The particle $b a$ is often used as an functional word in Chinese Mandarin at the end of a sentence. Semantic studies of SFP $b a$ can be divided into two distinct genres. Firstly, traditional grammar was inclined to believe that SFP $b a$ contains several different meanings. Chao Yuanren (1979) proposed that there were two " $b a$ "s--one is the weak form of $b a$, conveying suggestion or providing alternative propositions; the other is the fusion of " $b u$ " and " $a$ ", which can be used in yes-no questions and declaratives with the speaker's speculation. Lü Shuxiang (1980) identified various cases where $b a$ could occur, including conjectures, expressions of uncertainty, inferential interrogatives, orders, requests, speech acts of agreement and other functions of politeness. While Shao Jingmin (1993) argued that $b$ a expresses the meaning of speculation and negotiation or suggestion, having combined the thoughts of Lü Shuxiang (1982).

However, instead of discriminating whether $b a$ contains one or two meanings, identifying the basic function of $b a$ is their research orientation. Characterized as a modal word, $b a$ was utilized to make speculation and ask for confirmation (Xu 2003). Qu Chengxi (1998) proposed that the main function of $b a$ was to express hesitation and suspicion of the speaker. While the meaning of $b a$ focused on location of the spectrum from confirmation (Zhou \& Cen 2008; Zhou 2009). In short, no agreement is reached about how many distinct meaning that $b a$ contains.

\subsubsection{Syntactic studies}

Traditionally, functional words or particles are regarded as non-grammatical units within a sentence. However, $\mathrm{Li}$ (2006) claimed that SFPs enjoy an indisputable syntactic position. From the format of a sentence that SFPs occur, it is reasonable to postulate that they occupy certain positions in a syntactic tree. Related to tense, aspect, or question marking, some SFPs do have certain grammatical functions, like Chinese particles " $m a$ " " $a$ " " $n e$ "

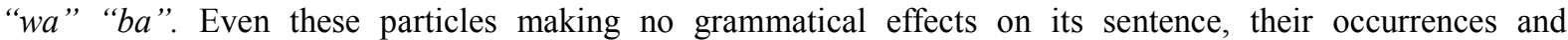
distributions are not random; especially when two or more particles are attached to the end of a clause, they are usually arranged in a rigid order instead. A more vivid example appears in German: Die Kuchen wird in der (SFPs) Party aufgegessen werden (English: The cake will be eaten in the party).

Additionally, there is no consensus about what kind of clause that $b a$ could attach to (Hu 1993; Lü 1980; Zhu 1982; Lu 1984; Qi 2002; Xu 2003) or which syntatic position in the tress that ba belongs to (Hu 1981; Zhu 1982; Hu 1993; Zhang 2000; Qi 2002; Zhao \& Shi 2011) in the previous literature.

\subsubsection{Pragmatic studies}

The pragmatic function has attracted most researchers to analyze SFP $b a$. Ran Yongping (2004) believed that $b a$ has negotiating function when used in a sentence, which can soften the mood of this sentence. Mitigation is one such pragmatic strategy originally defined as reducing the possible unwelcome perlocutionary effects on the addressee (Fraser 1980) and later as modifying the illocutionary force of a speech act (Hengeveld 1989, Hengeveld \& Mackenzie 2008, Thaler 2012). As revealed in the discussion of four Dutch modal particles by Vismans (1994), particles were also found to have mitigating functions. Li and Thompson (1981) also ascribe the function of politeness and mitigation to SFP $b a$ (solicit agreement) and $y a$ (reduce forcefulness). Lee-Wong (1998) analyzed the way Chinese speakers employ the particles " $a$ " " $b a$ " " $n e$ " in direct requests in relation to such contextual constraints as relative social distance, relative power and relative weighting of the degree of imposition. Against Mandarin $b a$ as a modal element, Fang \& Hengeveld (2020) showed that $b a$ should be treated as having a unified mitigating function, co-occurring with modal elements.

Therefore, reviewing literature can shed on some light on the present study. Pragmatic studies of ba as a mitigator however are still deficient when analyzing its illocutionary force of conventional utterance. In order to substantiate our claims (SFP $b a$ could attach to four clause types: declaratives, interrogatives, imperatives and exclamatives and play an inevitable pragmatic part of performing the illocutionary force), diverse methods and more data should be adopted in order to make it much more scientific and persuasive.

\section{Data collection and analysis}

\subsection{Research Methodology and Data Collection}

In this article, quantitative and qualitative methods were adopted to explore the sentence final particle $b a$. Minimal pairs were mainly used as a basic method to get some findings, such as deletion, adding and comparison.

All data was taken from Beijing Language and Culture University Corpus (http://bcc.blcu.edu.cn). For the examples from our sub-corpus, which was retrieved from BCC, each one is automatically assigned a number according to the order of appearance with “吧” as the keyword for searching. Since there are 1,832,973 cases in total, only the first twenty pages of data $(2,000)$ were randomly selected to conduct quantitative analysis in this paper as well as the author's own knowledge. Conversely, qualitative analysis was conducted by analyzing certain typical examples based on the illocutionary force of $b a$ in different clause contexts. 


\subsection{Contextual Interpretation of SFP ba}

Numerous scholars claimed that Chinese particles can not be tagged onto exclamatives though, the current article accords to the conception that $b a$, as a speech act marker, could be given to declaratives or yes-no questions with uncertainty, non-yes-no questions with requesting a direct answer and imperatives for suggestion (Deng Dun 2015). In this section, we will show that different illocutionary force of $b a$ and its generalized mitigating functions, which triggers specific effects depending on the context or speech act in which it occurs. Therefore, we organize this part in terms of four clause types: declaratives, interrogatives, imperatives and exclamatives.

3.2.1 Declaratives

3.2.1.1 The basic "uncertainty" account

On account of the previous literature, SFP $b a$ is described as an imperative construction or a marker of "weak information transmission" though (Wang 1984; Xu 2008), here we emphasize its function as a "marker of uncertainty" (Hu 1981; Zhang 2013; Zhou \& Cen 2009 ) .

(A girl who wanted to sign in Zhenai Web said to a print shop owner that she needed to edit her picture and then put a watermark on it. Then the owner said,)

(1a) Mei kaitong huiyuan dabuliao.

No (opening) member can't print.

'No member can not put a watermark on your picture." (CCL 1.45)

(1b) Mei kaitong huiyuan dabuliao BA.

No (opening) member can't print $B A$.

'No member $\underline{m a y}$ not put a watermark on your picture." (CCL 1.45)

(2a) Bukeneng, zuotian wanshang xia name dayu, ni zenme hui lai?

Not possible, yesterday evening down so big-rain, you how possibly come?

'It's impossible, yesterday evening there was such a heavy rain, how could you possibly return?'

(2b) Bukeneng BA, zuotian wanshang xia name dayu, ni zenme hui lai? Not possible $B A$, yesterday evening down so big-rain, you how possibly come?

'It's presumably impossible, yesterday evening there was such a heavy rain, how could you possibly return?' (Quoted from Xu 2008)

As we can see from the examples above, a declarative like (1) \& (2) can be added a SFP ba. However, the meaning of (a) and (b) is slightly different. (1a) means that if the girl could put a watermark on her picture unless she was a member. The utterer knows the truth for sure and describes what he has known, leaving no space for negotiation. While having attached a $b a$ to declaratives, it mitigates the assertiveness of the statement, confounding a little uncertainty or speculation. The same truth is applicable for sentence (2). When the assertion tends to be unsure, it is conventionally inserted some modal adverb, such as may and presumably. Therefore, it is shown that a SFP $b a$ plays the same role as "may" or "presumably" with an uncertain illocutionary force. More examples indicate that $b a$ could soften the harshness of criticism or a negative face of the addressee with a prolonged duration on the final syllable. In example (3), the teacher was blaming the boy for his lying.

(3) (A student broke the school window and lied to his teacher. Then the teacher asked him to clean the classroom for a month and said,)

Zhidao cuo le BA.

Know wrong [+perfect] BA. (CCL 3.75)

'You have known what was wrong.'

(4) (When the son was leaving for a football match, the mother told him that he should carry a thicker jacket but the son wouldn't listen and came back coughing and sneezing. Then the mother said,)

Ganmao le BA.

catch a cold [+perfect $] \quad B A .($ Chu \& Li 2004)

'You've caught a cold.' (I had told you to be careful, but you didn't listen.)

3.2.1.2 The collocation of ba in declaratives

As mentioned above, in the CCL ba felicitously co-occurs with adverbials of possibility like dagai (probably), keneng (possibly), yехu (presumably), hиохи (perhaps), dayue (approximately), etc. Meanwhile, ba could coappear with certainty adverbs such as yiding/kending (certainly), haowu yiwen (undoubtedly) as well as auxiliary verbs of probability like yinggai (should), gaibuhui (should not/will not), zongbuhui/zongbuneng (may not).

(5) Dagai shiyinwei women li shandong henjin $B A$.

Dagai shizai fumu mianqian bijiao cuiruo $B A$.

(6) $\underline{\text { Keneng }}$ jiushi women zhedairen de xianzhuang $B A$. Keneng yu qianduan shijian de dizhen youguan $B A$.

(7) $\underline{Y e x u}$ shi wo rensheng yueli haibugou $B A$. $\underline{Y e x u}$ shi wode guanxin fangshi budui $B A$. 


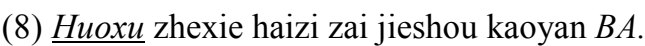

Huoxu shi wo ziji budongde zhenxi $B A$.

(9) Dayue shi wei fu xinci qiang shuo chou $B A$.

Dayue shi women zhuiqiu de zuigao jingjie le $B A$.

(10) Wo xiang kending shi diren de yinmou $B A$. (Quoted from Xu 2008)

Ta yiding shi yige shicheng shanliang de ren $B A$.

(11) Wo youxie yiwai, ta gaibushi zai dengwo $B A$.

Ni gaibuneng shi shebude huaqian qingke $B A$.

(12) Zongbuhui meici dou jiao ni yige nvsheng chuchai $B A$.

Fanzheng wo dai le liudong zijin, zongbuneng shaoyu ershiwan $B A$.

(Quoted from Xu 2008)

\subsubsection{Interrogatives}

The interrogatives in which $b a$ occurs are often tag questions, which are more consultative than assertions and less inquisitive than yes-no questions (Ji 2019). Fraser (1980) pointed out that tag questions, which sound less inquisitive and more confirmation seeking, are used by the speaker to mitigate the force of a speech act. Here we discuss two types of questions: WH-questions and alternative questions (we regard "V+NOT+V" question as a variant of alternative questions in this paper).

Based on Li and Thompson (1981), $b a$ has the effect of soliciting agreement from the speaker in interrogative sentences. Without $b a,(13)$ would be a statement for sure rather than a question; when attached $b a$, the original interrogative force is soften. Therefore, such that the addresser is not asking a question but seeking confirmation from the addressee.

(13a) Ta buhui zuo zheyang de shi.

He not will do this manner [+possession] thing.

'He wouldn't do such things.'

(13b) Ta buhui zuo zheyang de shi BA?

He not will do this manner [+possession] thing $B A$ ?

'He wouldn't do such things.' (Wouldn't you agree?)

\subsubsection{WH-questions}

WH-questions request the filling of an information gap by using interrogative words including what, when, which, where, why, how, etc.

(14a) Ni shenme shihou lai?

You what time come?

'What time/when do you come?'

(14b) Ni shenme shihou lai BA?

You what time come $B A$ ?

'What time/when do you come BA?' (CCL 17.15)

The answer of the question "When do you come?" is an unpredictable time for the hearer. The answer would be the same after adding a SFP ba though, the sentence mood may sound pertinent and the interrogative force is reduced, conveying the illocutionary force of a more explicit invitation or request to provide an answer.

3.2.2.2 Alternative questions

Alternative questions provide an either...or choice for the addressee, usually with the expression haishi (or); and "V+NOT+V" questions likewise offer two alternatives of an event, but in this case one is the negative counterpart of the other. However, since no such alternative questions samples were found in CCL (only several declaratives to express the speaker's uncertainty, like Wuji fangshuitai haoxiang shi 17 haishi 18 ba), here we quote an example by Zhu (1982).

(15) $N i$ chi fan haishi chi mian BA?

You eat rice or eat noodles $B A$ ?

'Do you eat rice or noodles?' (Please choose one option and tell me.)

(16a) Ni jiu shuo qu bu qu?

You just say go not go?

'Tell me whether you will go or not?'

(16b) $N i$ jiu shuo qu bu qu BA?

You just say go not go $B A$ ?

'Would you tell me whether you will go or not?' (CCL 4.83)

(17) $A i$ lai bu lai BA.

Like come not come $B A$.

'(It doesn't matter to me) whether you'd like to come or not.' (CCL 15.12)

As shown in (16a) and (16b), the speaker wants to know the hear go or not go somewhere, but the tone or mood sounds more pertinent or softer in (16b), which leads to lessen the negative face of the hearer, achieving 
solidarity and harmony. "V+NOT $+\mathrm{V}$ " is conventionally the format with a strong tone in Chinese Mandarin. A more typical sample in (17) has manifested to weaken or mitigate the speaker's criticism and dissatisfaction through employing a SFP $b a$, also defused the illocutionary force of threatening to the addressee.

3.2.3 Imperatives

Imperatives principally refer to note or pertain to the mood of the verb used in an unavoidable obligation, requirement and necessity or something that demands attention and action, which have strong intention from the speaker, leaving no room for the hearer to deny or against the order.

(18a) Gun.

Get out.

(18b) Gun BA (ni).

Get out $B A$ (you).

(19a) Bang bang wo.

Help help me.

'Help me.'

(19b) Bang bang wo BA.

Help help me $B A$.

'Please help me.'

As we can see, "Gun" in (18a) conveys the speaker's anger, making no consultation for the hearer due to its imperative mood in Chinese. While, $b a$ as a mitigator, the relationship between the addresser and the addressee may be changed into alleviation in (18b) since the sentence pattern "V+BA+NI" delivers a playful tone in certain dialects. For example, "Ye xiong ba ni/La dao ba ni" equals to "I don't believe in you." in Jiang Huai Mandarin (especially for Chuzhou dialect), softening the intensity of negative emotions in imperatives. Moreover, it is evident that (19b) shows more politeness and rapprochement than (19a) with the help of $b a$. In other words, $b a$ is featured as the illocutionary force of an euphemism addition to request like "please", allowing for the possibility and freedom of a refusal action or opposition imposed by the speaker.

3.2.4 Exclamatives

Mandarin exclamatives, expressing the speaker's emotions (Gao 1986), can be made explicit by having exclamative markers such as demonstrative pronouns zheme/name, adverbs zhen/hao/tai as well as particles (like a). $B a$ can hardly co-occur with these Mandarin exclamatives resulting from the contradiction of the exclamative mood and semantic function of undetermined intention or uncertainty. (Zhou 2009; Lu 2007; Zhao \& Sun 2015). However, we still find such certain samples ( 73 cases of format "Tai+BA!" in CCL).
(20) $\mathrm{Na}$ ni ye tai lihai le BA!
That you're also too impressive [particle] $B A$ !
'How impressive you are!'
(21) Nide qunzi ye tai haokan le BA!
Your skirt also too beautiful [particle] $B A$ !
'How beautiful your skirt is!'
(22) Tai xingfu le BA!
Too happy [particle] $B A$ !
'How happy (I am)!'
(23) $\mathrm{Ni}$ ye tai kuazhang le BA!
You're also too exaggerated [particle] $B A$ !
'How exaggerated you are!'

According to Siemund (2015), exclamatives "express the speaker's affective response to a situation". On the basis of phonetic experiments by Chen (2007), the explicit marker tai exhibits the highest pitch as well as a longer duration with the word right after it taking a lower pitch. Above four language environment have strengthened the speaker's positive compliment with a stressed and falling tone on $b a$, which is distinct from the justification from Fang \& Hengeveld (2020): $b a$ in exclamatives conveyed strong negative emotions of the utterer, like xiaoqi (complaining) and guofen (criticizing). However, the proportion of such examples in CCL is relatively small.

3.2.5 Brief Summary

In this section, we have minutely elucidated the pragmatic function sentence final particle $b a$ within different contexts. These effects can be summarized as follows: First and foremost, when $b a$ is attached to declaratives, it has the illocutionary force of performing the speaker's uncertainty, especially co-occurring with adverbials of possibility, auxiliary verbs of probability and adverbs of certainty. Secondly, the illocutionary force of seeking confirmation, inviting to answer and defusing or mitigating the negative face is provided by the interrogatives. Then a more polite and positive intention of the speaker has achieved through employing $b a$ in imperatives and exclamatives. 


\section{Conclusion and limitations}

4.1 Conclusion

Based on the previous studies of particle $b a$, this article further analyzes which clause types that $b a$ can attach to and the pragmatic functions of $b a$ within speech act theory. Major findings are as follow:

Firstly, as to clause types that $b a$ can attach to, we have argued that $b a$ can appear in declaratives, interrogatives, imperatives and exclamatives, which is inconsistent with predecessors. Specifically, when $b a$ is tagged to declaratives, it is likely to collocate with modal adverbs of possibility (dagai, keneng, yexu, huoxu, dayue), auxiliaries of probability (yinggai, gaibuhui, zongbuhui/zongbuneng) and adverbs of certainty (yiding/kending, haowu yiwen). As for interrogative clauses, ba appears in wh-questions and alternative questions, including a variant format "V+NOT+V" questions. Meanwhile, particle $b a$ can be used at the end of imperatives and exclamatives to deliver the speaker's harmonious and positive intention.

Secondly, in view of Deng Dun's observation (2015), which claimed that $b a$ can bring about different illocutionary force when occurring in various clause types. $B a$ performs the illocutionary force of telling the addressee some information that the declaratives have provided with uncertainty. At the same time, other than Deng's result (2015), we have testified that $b a$ assigns to the interrogatives the illocutionary force of demanding a direct affirmation, diminishing a negative effect. Another kind of illocutionary force $b a$ brings is attaining a high degree of politeness and leaving more space for negotiation within imperatives and exclamatives.

\subsection{Limitations}

Due to the limited time and research ability of the author, there is still a great room to improve and several limitations of this article covering two aspects: the corpus scope and theoretical analysis.

Firstly, unavailable to the Peking CCL Corpus, the current study had to apply Beijing Language and Culture University Corpus. A small quantity of samples overlapped many times with no time stamp, wasting time to classify and select typical or valid data.

Secondly, the current study aims to estimate the pragmatic functions of SFP $b a$ within the speech act theory, which seems to be a generalized framework. Certain inference depends on the author's subjective justification or intuition rather than specific theoretical evidence. Therefore, it is hoped to integrate speech act theory with other theoretical structures, such as the framework of Functional Discourse Grammar by Hengeveld and Mackenzie (2008) or Linguistic Regulation Theory by Huo (2004) in the future.

\section{References}

Austin, J. L. (1962). How to Do Things with Words. Oxford: Oxford University Press.

Chao, Yuanren. (1979). Hanyu kouyu yufa (A Grammar of Spoken Chinese). Beijing: Shangwu Yinshuguan (Commercial Press).

Chen, Hu. (2007). Jiyu yuyinku de hanyu gantanju gantan yudiao yanjiu (A study of Chinese exclamatory sentence and intonation based on sound corpus). Hanyu xuexi (Chinese Language Learning) 5, 45-55.

Chu, C. Chauncey., \& Bin, Li. (2004). Xiandai hanyu jumo qingtai xuci jiqi yingyi--yi " $b a$ ” de yupian gongneng weili (Translating Modern Chinese utterance--final particles into English: a case study of the discourse function of ba). Waiyu xuekan (Foreign Language Research) 6, 1-10.

Daniel, Marcu. (2000). Perlocutions: The Achilles' heel of speech act theory. Journal of Pragmatics 32(12), $1719-1741$.

Deng, Dun. (2015). The syntacticization of illocutionary forces and the root vs. non-root distinction: evidence from the sentence-final particle $b a$ in Mandarin. Lingua 162, 32-55.

Di, Zhang., Zhibo, Wang. \& Robert, Elliott. (2018). A Case Study of the Sentence Final Particle " $B a$ " 's Pragmatic Functions in Chinese-speaking Children. International Journal of Early Childhood Education Care 7, 60-77.

Fang, Hongmei. \& Hengeveld, Kees. (2020). A mitigator in Mandarin: the sentence-final particle ba. Open Linguistics 6(1), 284-306.

Fraser, Bruce. (1980). Conversational mitigation. Journal of Pragmatics 4(4), 341-50.

Gao, Mingkai. (1986). Han fa (On Chinese Grammar). Beijing: Shangwu Yinshuguan (The Commercial Press).

Hengeveld, Kees. (1989). Layers and operators in functional grammar. Journal of Linguistics 25(1), $127-57$.

Hengeveld, Kees. \& Lachlan, Mackenzie. (2008). Functional Discourse Grammar: A Typologically-based Theory of Language Structure. Oxford: Oxford University Press.

Hengeveld, Kees. \& Rafael, Fischer. (2018). “A'ingae (Cofán/Kofán) operators.” In Systems of tense, aspect, modality, evidentiality and polarity in Functional Discourse Grammar. Open Linguistics 4, 328-55.

Holtgraves, T. (2002). Handbook of Communication Competence. The Deutsche Nationalbibliothek.

$\mathrm{Hu}$, Mingyang. (1993). Chenshu yudiao he yiwen yudiao de " $b a$ ” zi ju (Statement intonation and questioning intonation of " $b a$ " sentences). Yuwen jianshe (Language Planning) 5, 32.

Hu, Yushu. (1981). Xiandai hanyu (Contemporary Chinese Language). Shanghai: Shanghai jiaoyu chubanshe 
(Shanghai Educational Publishing House).

Huo, Y. S. (2004). Mitigation and Pragmatics as a Linguistic Regualtion Theory. Kunming: Yunnan University Press.

Jin, Jingji. (2016). Syntax, Semantics and Pragmatics of the "V (Vp)+Ba+Ni" Format. [MA], Yanbian University.

Jin, Qiaomei. (2018). Multi-perspective Analysis of "X+Ba+Personal Pronoun”. [MA], Central China Normal University.

Levinson, S. C. (1983). Pragmatics. Cambridge: Cambridge University Press.

Li, Charles N. \& Sandra, A. Thompson. (1981). Mandarin Chinese: A Functional Reference Grammar. Berkeley: University of California Press.

Liu, Mengting. (2014). The Functional Analysis of Chinese modal " $n$ " " $m a$ " " $b a$ " " $a$ " and in the study of Teaching Chinese as a Foreign Language. [MA], Jilin University.

Lu, Jianming. (1984). Guanyu xiandai hanyu li de yiwen yuqici (On interrogative mood words in modern Chinese). Zhongguo yuwen (Studies of the Chinese Language) 6, 330-337.

Lu, Yingshun. (2007). " $b a$ " de yufa yiyi zai tan (The grammatical meaning of "ba" revisited). Shijie hanyu jiaoxue (Chinese Teaching in the World) 3, 79-85.

Lü, Shuxiang. (1980). Xiandai haiyu babaici (Modern Chinese Eight Hundred Words). Beijing: Shangwu Yinshuguan (Commercial Press).

Qi, Huyang. (2002). "ne” de yiyi fenxi he lishi yanbian (Analysis of the Meaning and Historical Evolution of the Word "ne"). Shanghai shifan daxue xuebao (zhexue shehui kexueban) (Journal of Shanghai Normal University (Philosophy \& Social Sciences Edition)) 1, 34-45.

Qu, Chengxi. (1998). Hanyu gongneng yufa chuyi (On Chinese Functional Grammar). Shijie hanyu jiaoxue (Chinese Teaching in the World) 4, 28-42.

Ran, Yongping. (2004). Yanyu jiaoji zhong " $b a$ " de yuyong gongneng jiqi yujing shunyingxing tezheng (The Pragmatic Function of " $\mathrm{Ba}$ " in Verbal Communication and Its Contextual Adaptation). Xiandai waiyu (Modern Foreign Languages) 4, 340-349, 436.

Ren, Erqing. (2021). Jiyu yuyi jineng qianxi qingtai renzhi zhuci “ba” he“だろう” (Analysis of the modal cognitive auxiliaries “ $b a$ ” and “だろう” based on semantic functions). Jingu wenchuang (JinGu Creative Literature) 11, 108-109.

Shao, Jingmin. (1993). "ba” zi yiwenju jiqi xiangguan jushi bijiao (Comparison of "ba" question sentences and their related sentences). Disijie guoji hanyujiaoxue taolunhui lunwenxuan (Selected Papers from the Fourth International Symposium on Teaching Chinese as a Foreign Language) 4, 225-233.

Song, Mei, Lee-Wong. (1998). Face support - Chinese particles as mitigators: A study of ba a/ya and $n e$. Pragmatics 8(3), 387-404.

Song, Hui. (2002). " $b a$ " de yuyi tezheng — jiantan xiandai hanyu gouci chengfen jiqi queli biaozhun (The Semantic Characteristics of " $\mathrm{Ba}$ "--Another Discussion of Modern Chinese Constructions and the Criteria for Establishing Them). Changchun jiaoyu xueyuan xuebao (Journal of Changchun Education Institute) 2 , 29-32.

Thaler, Verena. (2012). Mitigation as modification of illocutionary force. Journal of Pragmatics 44(6-7), 907919.

Tong, Shengqiang. \& Sun, Xiaowen. (2005). " $b a$ " de yuyi fazhanguiji ji yufa xingzhi (On the Morpheme " $B a$ " in Mandarin). Jinan daxue huawen xueyuan xuebao (TCSOL Studies) 1, 53-58.

Wang, Li. (1984). Wangli wenji. Jinan: (Shangdong Jiaoyu Chubanshe) Shangdong Education Press.

Wang, Wenfang. (2009). Xiandai hanyu yuqici " $b a$ ” yanjiu zongshu (A Summary of Modern Chinese Mood Word "Ba" Study). Yancheng shifan xueyuan xuebao (renwen shehui kexue ban) (Journal of Yancheng Teachers University (Humanities \& Social Sciences)) 2, 87-89.

$\mathrm{Xu}$, Gaosong. (2015). "Kan $b a$ " de yuyi leixing ji yuyong xiaoguo fenxi (Analysis of the semantic types and pragmatic effects of "Kan ba”). Anhui wenxue (Xia ban yue) (Anhui Literature (second half of the month)) 3, 107-108.

Xu, Jingning. (2003). Yuqi zhuci " $b a$ " de qingtai jieshi (Modality Interpretation for the Tone Particle " $b a$ "). Beijing daxue xuebao (zhexue shehui kexueban) (Journal of Peking University (Philosophy and Social Sciences)) 4, 143-148.

$\mathrm{Xu}$, Jing Ning. (2008). Xiandaihanyu huayu qingtai yanjiu (Research on Modality of Modern Chinese Discourse). Beijing: Kunlun Chubanshe (Kunlun Press).

Yuan, Yun. (2003). "V+Ni de+N+Ba!" yuyi fenxi ("V+Ni de+N+Ba!" Semantic Analysis). Tianzhong xuekan (Journal of Tianzhong) 1, 115-116.

Zeng, Qin. (2012). The Meaning Analysis of Chinese Particles "ne” "ba” " $m a$ ” " $a$ ” and Their Teaching. [MA], Jiangxi Normal University.

Zhang, Weiran. (2012). A Study on the Semantic Meaning of the Final Modal Particles " $M a$ " “ $B a$ ” "Ne”. [MA], 
Peking University.

Zhang, Xiao Zhuan. (2013). Lun "haoba" huayu biaoji de xingcheng ji huayu gongneng (Discussing the formation and the discursive function of the discourse marker: "haoba"). Lilunjie 9, 160-162.

Zhang, Yisheng. (2000). Xiandai hanyu xuci (Modern Chinese function words). Shanghai: Huadong shifan daxue chubanshe (East China Normal University Press).

Zhao, Chunli. \& Shi, Dingxu. (2009). Yuqi, qingtai yu juzi gongneng leixing (Mood, modality and sentence type). Waiyu jiaoxue yu yanjiu (Foreign Language Teaching and Research) 4, 483-500, 639.

Zhao, Chunli. \& Li, Sun. (2015). Jumo zhuci " $b a$ " de fenbu yanzheng yu yuyi tiqu (On the distributional verification and semantic extraction of the sentence-final particle "ba") Zhongguo yuwen (Studies of the Chinese Language) 2, 121-32.

Zhou, Shihong. \& Cen, Yunqiang. (2008). Shi lun yuqici " $b a$ " de qingtai yiyi (On the modal meaning of modal word "ba"). Beifang luncong (The Northern Literary Studies) 6, 56-59.

Zhou, Shihong. (2009). "ba" de yiyi gongneng zaiyi (Grammatical Meaning and Discourse Function of " $b a$ " Revisited). Yuyan jiaoxue yu yanjiu (Language Teaching and Linguistic Studies) 2, 16-22.

Zhu, Dexi. (1982). Yufa jiangyi (Grammar Finder). Beijing: Shangwu Yinshuguan (Commercial Press). 